\title{
A INSTITUCIONALIZAÇÃO DO REGIME DE COMPETÊNCIA NO SETOR PÚBLICO ${ }^{1}$
}

\section{THE INSTITUTIONALIZATION OF THE REGIME OF COMPETENCE IN THE PUBLIC SECTOR}

\section{LA INSTITUCIONALIZACIÓN DEL RÉGIMEN DE COMPETENCIA EN EL SECTOR PÚBLICO}

Juliane Pereira Lemos, Bacharel em Ciências Contábeis/UFES. Endereço Profissional: Av. Fernando Ferrari no 514 - Prédio da Reitoria - Goiabeiras - 29075-910 - Vitoria, ES. Email:juliane.pereiralemos@gmail.com.

Luiz Eduardo Pereira Lemos, Bacharel em Ciências Contábeis/UFES. Endereço Profissional: Av. Fernando Ferrari no 514 - Prédio da Reitoria - Goiabeiras - 29075-910 Vitoria, ES. E-mail: leduardoplemos@gmail.com.

Janyluce Rezende Gama, Doutora em Ciência da Informação/UNB. Professora do Dep. Ciências Contábeis da Universidade Federal do Espírito Santo. Endereço Profissional: Av. Fernando Ferrari no 514 - Prédio da Reitoria - Goiabeiras - 29075-910 - Vitoria, ES. Tel.: (27) 3335 2602. E-mail: janylucegama@gmail.com.

Douglas Roriz Caliman, Mestre em Administração/UFES. Professor do Dep. de Ciências Contábeis da Católica de Vitória Centro Universitário. Contador Geral da Universidade Federal do Espírito Santo. Endereço Profissional: Av. Vitória, nº 950, Forte São João, Vitória/ES - 29017-950. Tel.: (27) 31455343 - douglasufes@ yahoo.com.br.

\section{RESUMO}

A contabilidade aplicada ao setor público encontra-se em um processo de mudanças. Entre elas a implementação do regime de competência. O objetivo é analisar a institucionalização, de acordo com Tolbert e Zucker (1999), de novos procedimentos ligados a convergência da Contabilidade Internacional ao Setor Público. Adotando como metodologia a abordagem qualitativa, com pesquisa descritiva e documental, por meio da Análise das Demonstrações Contábeis, Notas Explicativas e Relatórios de Controle Interno publicados no portal do Governo do Estado do ES. Buscou-se analisar as ações e procedimentos adotados no período de 2013 a 2015, no qual ocorreu a adoção dos novos procedimentos trazidos pelas Normas Brasileiras de Contabilidade Aplicadas ao Setor Público. Os resultados permitiram observar a evolução na implementação de procedimentos patrimoniais como depreciação, amortização, ajustes para perdas, provisões, apropriações por competência das despesas com pessoal e passivos contingentes. Porém, a adoção do regime de competência para procedimentos contábeis patrimoniais no setor público ainda não foi institucionalizada, já que os seus efeitos só poderão ser analisados no longo prazo.

Palavras-chave: Setor Público; Regime de Competência; Institucionalização; Contabilidade Pública.

\footnotetext{
${ }^{1}$ Artigo submetido em 19/07/2017, revisado em 15/11/2017, aceito em 18/06/2018 e divulgado em 10/07/2018 pelo Editor João Carlos Hipólito Bernardes do Nascimento, após double blind review.
}

GєCont, v. 5, n. 1, Floriano-PI, Jan-Jun. 2018. 


\begin{abstract}
Accounting applied to the public sector is in a process of changes. Among them the implementation of the regime of competence. Thus, this study aims to analyze the contributions of changes in Brazilian public accounting, based on the Competence Regime. Adopting as a methodology the qualitative approach, with descriptive and documentary research, through the analysis of the Financial Statements, Explanatory Notes and Internal Control Reports published in the State Government website. It was sought to analyze the actions and procedures adopted in the period from 2013 to 2015, in which the adoption of the new procedures brought by the Brazilian Accounting Standards Applied to the Public Sector occurred. The results showed the evolution in the implementation of equity procedures such as depreciation, amortization, adjustments for losses, provisions, appropriations for competence of personnel expenses and contingent liabilities. However, the adoption of the regime of competence by the public sector has not yet been fully institutionalized, since its effects can only be analyzed in the long term.
\end{abstract}

Keywords: Public Sector; Accrual method; Institutionalization; Public Accounting.

\title{
RESUMÉN
}

La contabilidad aplicada al sector público se encuentra en un proceso de cambios. Entre ellos, la implementación del régimen de competencia. Por lo tanto, este estudio tiene como objetivo analizar las contribuciones de los cambios en la contabilidad pública brasileña, con base en el Régimen de Competencias. Adoptando como metodología el enfoque cualitativo, con investigación descriptiva y documental, a través del análisis de los Estados Financieros, Notas Explicativas e Informes de Control Interno publicados en el sitio web del Gobierno del Estado. Se buscó analizar las acciones y procedimientos adoptados en el período de 2013 a 2015, en el cual se produjo la adopción de los nuevos procedimientos traídos por las Normas Contables Brasileñas Aplicadas al Sector Público. Los resultados mostraron la evolución en la implementación de los procedimientos de equidad tales como depreciación, amortización, ajustes por pérdidas, provisiones, asignaciones por competencia de gastos de personal y pasivos contingentes. Sin embargo, la adopción del régimen de competencia por parte del sector público aún no se ha institucionalizado por completo, ya que sus efectos solo pueden analizarse a largo plazo.

Palabras clave: Sector público; Método de acumulación; Institucionalización; Contabilidad pública.

\section{INTRODUÇÃO}

globalização de mercados, o aumento do risco dos ambientes econômicos e
organizacionais (MINTZBERG, 1995), a complexidade de se colocar em
prática técnicas de gerenciamento e controle (ANTONY, 1965), a exigência de convergência a padronização contábil internacional (LEMES; SILVA, 2007; IFAC, 2008), e a necessidade de mensurar e medir o desempenho operacional (ANTONY; GOVINDARAJAN, 2001), coloca os gestores em nível de complexidade de gestão e tomada de decisão ainda maior (LIMA et al., 2011). A Contabilidade Aplicada ao Setor Público (CASP) é aliada dos gestores públicos, uma vez que tem como finalidade gerar informações consistentes e tempestivas para a tomada de decisões em relação a gestão orçamentária, financeira e patrimonial (GAMA, 2015; NAIDOO, 2015). Portanto, para a tomada de decisão, seja na esfera pública ou não, é indispensável que as informações geradas pela contabilidade obtenham consistência, transparência em sua elaboração (QUINTANA; JACQUES; MACAGNAN, 2016). Segundo Lima e Castro (2009, p. 16), "a finalidade da Contabilidade Aplicada ao Setor Público é oferecer

GєCont, v. 5, n. 1, Floriano-PI, Jan-Jun. 2018. 
à sociedade, de maneira transparente e acessível, o conhecimento amplo sobre a gestão da coisa pública".

Assim, com o processo de adequação às normas contábeis internacionais promovido pela International Federation of Accountants (IFAC), por meio do International Public Sector Accounting Standards Board (IPSASB), autoridades do governo brasileiro uniram esforços para adotar o processo de convergência das normas contábeis às internacionais e à adoção de regime contábil de competência (BORGES et al, 2010; CRUVINEL; LIMA, 2011). Dessa maneira, o Brasil está vivenciando um período transitório de convergência da CASP ao padrão internacional, para que isso se efetive foram elaboradas as Normas Brasileiras de Contabilidade Aplicadas ao Setor Público (NBCASP) pelo Conselho Federal de Contabilidade (CFC) em 2008, assim como a elaboração dos Manuais de Contabilidade Aplicada ao Setor Público (MCASP), produzido pela Secretaria do Tesouro Nacional (STN).

Deve-se ressaltar que os benefícios gerados com a adoção do regime de competência para a contabilidade patrimonial do setor público estão atrelados a geração de informação útil para a tomada de decisões por parte dos gestores e comparabilidade entre os entes da Federação, além do registro e acompanhamento de transações que afetam o patrimônio antes de serem contempladas no orçamento (VIANA; GAMA, 2015).

O regime de competência é o método que reflete de forma mais aplicável o desempenho econômico no resultado do exercício, reconhecendo as receitas e despesas independentemente da entrada ou saída de recursos financeiros no caixa da entidade (CRUVINEL; LIMA, 2011). A adoção do regime de competência no setor público visa, além da melhoria na qualidade da informação contábil, promover maior controle e transparência nas contas públicas (GAMA; DUQUE; ALMEIDA, 2014).

Nesse contexto, objetivando sempre a melhoria na qualidade da informação contábilfinanceira, ou seja, aumentando a transparência e responsabilização dos recursos realizados pelos gestores públicos (CHAN, 2010), a convergência adotada pelo Brasil, tem o intuito de adotar as normas convergidas pelo CFC, no padrão das International Public Sector Accounting Standards (IPSAS), editadas pela IFAC. Por conseguinte, o CFC, órgão regulador das práticas contábeis no Brasil, a partir das normas contábeis da IFAC, reuniu um grupo de profissionais para a elaboração das NBCASP, em conformidade com os fundamentos da IPSAS. Após aprovação em audiência pública, no ano de 2008, surgiu as dez NBCASP e, em 2011, a décima primeira. Porém, em 4 de outubro de 2016, a NBC TSP EC ao ser publicada no Diário Oficial da União (DOU), revogou as resoluções do CFC que aprovaram as normas aplicáveis ao setor público NBC T 16.1 a 16.5, parte da NBC T 16.6 e as Resoluções $n^{\circ} 750 / 1993$, que dispõe sobre os Princípios de Contabilidade, e a $\mathrm{n}^{\circ} 1.111 / 2007$, que trata da interpretação dos princípios sob a perspectiva da área pública.

Dentre os principais pontos de transição na contabilidade pública tem-se a mudança de perspectiva contábil, antes centrada no controle orçamentário, passa a ser uma contabilidade com enfoque mais patrimonial, com a adoção do regime de competência para os ativos e passivos do Setor Público que passam a ser registrados em sua totalidade, havendo uma melhora na qualidade da informação e aperfeiçoando a gestão da coisa pública (CRUVINEL; LIMA, 2011; AMARAL; LIMA, 2013), pois estabelece que os efeitos das transações e outros eventos sejam reconhecidos nos períodos a que se referem, independentemente do recebimento ou pagamento, assim como a confrontação de receitas e despesas correlatas. Além disso, houve a adoção por parte da CASP de um Plano de Contas Aplicado ao Setor Público, este o qual é único para todo Estado brasileiro possibilitando uma melhor gestão e transparência no setor público. O processo de institucionalização das normas de contabilidade publica aos padrões internacionais possui diversos desafios ao redor do mundo, como falta de apoio político, falta de mão e obra qualificada, e um custo financeiro elevado (VANDERHOEK, 2005; BLONDAL, 2003). No Brasil não é diferente, a institucionalização das novas normas contábeis convergidas,

GєCont, v. 5, n. 1, Floriano-PI, Jan-Jun. 2018. 
passa pela falta de infraestrutura, falta de tecnologia, falta de especialização e treinamento dos servidores públicos (GARRIDO, 2012), além de um planejamento claro pelos órgãos reguladores (GAMA; DUQUE; ALMEIDA, 2014) e da resistência de alguns setores da administração pública em relação à abertura de suas informações ou, ainda, pelo entendimento errôneo de alguns de que a Contabilidade deve atuar passivamente e só registrar o que lhe é encaminhado (SILVA, 2012).

Mas, mesmo com todos os desafios elencados, várias mudanças já foram normatizadas para a CASP na última década, e na medida em que essas novas práticas contábeis são inseridas na Administração Pública com suas mudanças, tende-se a surgir repercussões na estrutura organizacional dos entes. Sob a ótica da teoria institucional, essas mudanças somente serão bem-sucedidas se forem institucionalizadas, os procedimentos que estão sendo implementados passarão por diferentes estágios de institucionalização, que em conjunto, representam o processo de institucionalização (CAMPOS; GAMA, 2013).

Portanto, o presente estudo tem por objetivo analisar as contribuições das alterações na contabilidade pública brasileira - principalmente a adoção e institucionalização do Regime de Competência - na qualidade da informação contábil, questionando: quais as contribuições que a nova contabilidade pública brasileira trouxe para a melhoria na qualidade e evidenciação das informações contábeis? Tendo como objetivo distinguir e analisar as ações que já contribuíram para a adoção dos procedimentos contábeis patrimoniais, do Governo do Estado do Espírito Santo. Para tanto, adotou-se como metodologia uma abordagem qualitativa, com pesquisa descritiva e documental, por meio da Análise das Demonstrações Contábeis, Notas Explicativas e Relatórios de Controle Interno publicados no portal do Governo do Estado do ES. Buscou-se analisar as ações e procedimentos contábeis adotados no período de 2013 a 2015, no qual ocorreu a adoção dos novos procedimentos trazidos pelas Normas Brasileiras de Contabilidade Aplicadas ao Setor Público, iniciados pelas Portarias STN n ${ }^{\circ}$ 634/13 e n. ${ }^{\circ}$ 548/15.

De acordo com Nascimento (2016), o representante do Brasil no IPSASB, essas regras iniciais já produzirão mudanças profundas na contabilidade dos entes federativos e aporte para a transparência das contas públicas, o mesmo afirma que com a convergência teremos um regramento mais sólido, já as normas que utilizamos hoje não possuem um detalhamento, como ocorre nas regras internacionais existentes, que agregam uma gama de informações patrimoniais em que se pode constatar com maior facilidade a realidade das contas públicas.

Desse modo, este estudo contribui para a ampliação do leque de pesquisas direcionadas ao setor público, visto que as mudanças incorporadas pela nova contabilidade pública influenciam na qualidade e evidenciação das informações contábeis patrimoniais, que consequentemente impactam na qualidade da transparência sobre as contas públicas e das ações e políticas públicas implementadas pelo estado.

\section{REFERENCIAL TEÓRICO}

\subsection{O PROCESSO DE CONVERGÊNCIA DA CONTABILIDADE PÚBLICA NO BRASIL}

A contabilidade, campo de conhecimento essencial para a formação dos agentes decisórios dos mais variados níveis, é fruto concebido da relação entre o desenrolar dos fatos econômico-financeiros e sua captação e processamento segundo os paradigmas de uma metodologia própria e potencializada pela racionalidade científica (IUDÍCIBUS; MARTINS; CARVALHO, 2008). Tem-se na contabilidade um instrumento para a obtenção de informações para uma melhor tomada de decisão, seja ela a contabilidade societária ou pública. O primeiro marco da contabilidade pública foi a Lei $\mathrm{n}^{\circ}$. 4.320/64, que estabeleceu regras para propiciar o controle das finanças públicas, bem como a construção de uma administração financeira e contábil sólidas no país, tendo como principal instrumento o orçamento público (MCASP, $7^{\mathrm{a}}$

GєCont, v. 5, n. 1, Floriano-PI, Jan-Jun. 2018. 
ed, parte III). Com a finalidade de convergir as práticas da contabilidade pública aos padrões internacionais, foi emitida a Portaria ${ }^{\circ}$. 184, de 25 de agosto de 2008, do Ministério da Fazenda, que evidencia a adoção de boas práticas contábeis, fortalecendo a credibilidade da informação, o que também facilitaria o acompanhamento e a comparação do desempenho dos entes públicos. Em virtude disso, atribui a STN a responsabilidade de editar o Plano de Contas Aplicado ao Setor Público (PCASP).

Com base na mencionada portaria, o CFC aprovou em 2008 as dez primeiras NBCASP, as quais vêm conferir e acrescentar à contabilidade aplicada ao setor público maior dinamismo e transparência no trato com o patrimônio público (PASSOS, 2012; GAMA, 2015). Com a emissão das NBCASP, a contabilidade pública passou a ter um novo foco, a denominada Contabilidade Patrimonial, com enfoque no patrimônio público, que segundo Nascimento (2008) traz benefícios macroeconômicos, microeconômicos e institucionais, apresentando dados mais próximos da realidade e refletindo no comportamento dos diversos fatores econômicos. Ademais, a adesão das normas citadas, favorece ao nível de compreensão das demonstrações contábeis pelos usuários da informação contábil, permitindo assim, um maior controle social.

Outro avanço ocorreu em 2009, com a alteração na matéria de transparência fiscal na Lei Complementar $n^{\circ}$. 101/2000 - Lei de Responsabilidade Fiscal, que tem como disposições preliminares, estabelecer normas de finanças públicas voltadas para a responsabilidade na gestão fiscal. Assim, segundo o Conselho Federal de Contabilidade (2016), o Brasil convergirá todas as regras de maneira escalonada. As primeiras normas tratarão de variações patrimoniais com e sem contraprestação, provisões, passivos contingentes e ativos contingentes, estoques e concessões de serviços públicos. Até 2021, pretende-se convergir 32 normas.

\subsection{REGIME DE COMPETÊNCIA}

A mudança na contabilidade ocorreu em seu objetivo, o qual deixa de ser apenas geradora de informações à administração e credores para informações financeiras a investidores e acionistas (HENDRIKSEN; VAN BREDA, 1999). Essa mudança foi impulsionada pelo crescimento rápido de aplicações em ações de empresas, pressionados pelo setor financeiro e da bolsa de valores. Com isso, a busca por princípios contábeis aumentou. A American Association of Accountants - AAA foi a pioneira ao publicar sua revisão, em 1948, sobre os Princípios Preliminares.

No Brasil, em 1972, foi divulgado o termo Princípios Contábeis (PC) pelo CFC, porém não se tinha uma definição sobre o que se tratava este termo. Foi apenas em 1981, que o termo Princípios Contábeis recebeu uma definição com a publicação da Resolução $\mathrm{CFC} \mathrm{n}^{\circ}$. 530 . Todavia, de acordo com Niyama e Silva (2008), pouco significado prático trouxe para a profissão, já que o que prevalecia nas empresas e também entre os contadores, era se as demonstrações financeiras estavam ou não em conformidade com a legislação vigente.

Em 1993, foi se redefinindo os PC com a publicação da Resolução CFC nº. 750, mas foi apenas em 2007 que houve um reflexo na Administração Pública Brasileira, com a publicação da Resolução CFC $\mathrm{n}^{\circ}$. 1.111, em que se interpretou os PC sob a ótica do setor público. Nesse contexto, o CFC mediante a Resolução no ${ }^{\circ}$ 1.367/2011 alterou ainda o apêndice da resolução $\mathrm{n}^{\circ} .750 / 93$ que trata dos princípios contábeis. O principal destaque, entretanto, está na visão do CFC sobre a aplicabilidade do princípio da competência ao setor público o que antes vivenciava uma mistura de regime de caixa e competência.

Com a revogação das Resoluções CFC nº. 1.111/2007 e 1.367/2011, e aprovação da NBC T SP - ESTRUTURA CONCEITUAL, em outubro de 2016, a obrigatoriedade do regime de competência ainda continua vigente sendo abordada na nova norma. Sobre o assunto, Nascimento (2008) explica que o momento de reconhecimento das alterações no ativo ou no

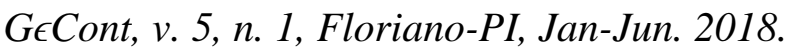


passivo, as quais resultam um aumento ou diminuição no patrimônio líquido, coincide com a ocorrência do fato gerador e não com recebimentos e pagamentos ocorridos na entidade. Com isso, demonstrações contábeis produzidas de acordo com esse regime, não informam ao usuário somente transações passadas que envolvem recebimentos e pagamentos, mas também obrigações a pagamentos e investimentos de recursos futuros.

À frente do processo de convergência no campo do setor público brasileiro, a STN, também se manifestou a respeito do regime de competência (CRUVINEL; LIMA, 2011), abrangendo em seu MCASP, publicado pela Portaria Conjunta STN/SOF n ${ }^{\circ}$. 1, de 10 de dezembro de 2014, $6^{\circ}$. edição, Parte III, p. 214, que: "as transações no setor público devem ser contabilizadas e seus efeitos evidenciados nas demonstrações contábeis dos exercícios financeiros com os quais se relacionarem, sendo reconhecidas, portanto, pelos respectivos fatos geradores". Diante disso, o regime de competência deve ser adotado por todas as instituições, sejam elas públicas ou privadas, pois o mesmo não só traz informações passadas, mas também previsões futuras reveladas com maior precisão possível sobre o patrimônio.

\subsection{A ACCOUNTABILITY PÚBLICA E A CONTRIBUIÇÃO NA TRANSPARÊNCIA NA GESTÃO PÚBLICA}

O termo accountability é um termo que não apresenta um conceito totalmente definido pelos diversos autores e estudiosos da contabilidade, mas vem sendo utilizado atualmente, principalmente em virtude da internacionalização das normas contábeis, que destacou a necessidade da melhoria da transparência e da prestação de contas para o setor público.

Todavia, o termo é reconhecido como sendo um dos novos conceitos empregados ao administrador público, não estando ligado apenas na transparência das gestões públicas, mas também confirma a possibilidade de responsabilização dos gestores, sendo admissível a aplicação de punições (SACRAMENTO, 2004). No Brasil, as entidades da administração direta e indireta da União, Estados, Distrito Federal e Municípios, conforme obriga a Constituição Federal de 1988, devem prestar contas da utilização dos recursos públicos, visando possibilitar à sociedade um controle da utilização desses recursos por parte dos gestores (GAMA; RODRIGUES, 2016). Esse mecanismo de prestação de contas e responsabilização no contexto do setor público é entendido por accountability governamental.

No contexto da Administração Pública percebe-se que a tendência é que a accountability governamental acompanhe o avanço de valores democráticos, tais como igualdade, dignidade humana, participação e representatividade (TRAVAGLIA, 2017). Assim, a accountability não deve restringir-se ao desempenho econômico e financeiro, mas contemplar também os demais fatores que norteiam a ação gerencial no setor público (TCU, 2014). Para Loureiro e Abrúcio (2002), o termo accountability é uma ferramenta de controle das políticas públicas adotadas pelos governantes, sendo essencial para um controle mais eficaz que contribua para a tomada de decisões que beneficie a sociedade. Desse modo, o termo está vinculado a responsabilidade social dos governantes, que devem prestar contas de seus gastos, informando a sociedade sobre a aplicação dos recursos arrecadados, sempre divulgando os atos do resultado de sua gestão de uma maneira de fácil entendimento para seus usuários.

O surgimento de ferramentas legais possibilitou que a padronização e a obrigatoriedade dos meios utilizados na prestação de contas por todos os entes federativos fossem mais acessíveis à sociedade, gerando informações que são debatidas pela sociedade no geral, garantindo que o Estado trabalhe de uma forma mais eficaz e eficiente.

A Lei de Responsabilidade Fiscal (LRF), Lei Complementar $n^{\circ}$. 101/2000, contribui para a melhoria na relação entre governo e sociedade, pois proporciona debates sobre a melhor maneira de se utilizar os recursos públicos, através de mecanismos de controle, fiscalização e transparência dos atos de gestão dos administradores públicos. Ademais, fortalece o 
planejamento e controle da prestação de contas já introduzidos de uma forma menos completa na Lei $\mathrm{n}^{\circ} .4 .320 / 64$. A LRF exige dos gestores a adoção de uma postura mais austera e prudente, focada no planejamento e no equilíbrio das finanças públicas (TRAVAGLIA, 2017). Esse instrumento surgiu na tentativa de melhorar a governança pública que possui como princípios a accountability, transparência e ética (TCU, 2014).

Nesse sentido, a Lei Complementar $n^{\circ}$ 131/09 acrescentou dispositivos à Lei de Responsabilidade Fiscal, a fim de determinar a disponibilização, em tempo real, de informações pormenorizadas sobre a execução orçamentária e financeira na União, Estados, Distrito Federal e Municípios, visando melhorar a accountability e transparência das informações no setor público (GAMA; RODRIGUES, 2016).

A LRF prevê no seu art. $1^{\circ}, \S 1^{\circ}$, a responsabilidade de se buscar transparência na gestão pública, enfatizando uma gestão responsável:

\footnotetext{
"A responsabilidade na gestão fiscal pressupõe a ação planejada e transparente, em que se previnem riscos e corrigem desvios capazes de afetar o equilíbrio das contas públicas, mediante o compromisso de metas e resultados entre receitas e despesas e a obediência a limites e condições no que tange a renúncia de receita, geração de despesas com pessoal, da seguridade social e outras, dividas consolidada e mobiliária, operações de crédito, inclusive por antecipação de receita, concessão de garantia e inscrição em restos a pagar" (BRASIL, 2000).
}

A LRF teve uma contribuição na transparência da gestão fiscal, ao assegurar que os relatórios fiscais, devam ter ampla divulgação, inclusive em meios eletrônicos de acesso público, proporcionando a participação da sociedade na discussão dos Plano Plurianual (PPA), Lei de Diretrizes Orçamentárias (LDO) e Lei de Orçamento Anual (LOA). O que reflete em seus dois pilares: responsabilidade e transparência (BRASIL, 2000, art. 48).

De acordo com Figueiredo et al. (2001), Cruz et al. (2001) e Tolentino et al. (2002), além de determinar regras, a LRF faz inovações ao motivar o controle do gasto público através de dispositivos de transparência; uma comum no mercado, onde os agentes econômicos necessitam de informações confiáveis para a tomada de decisões. Além disso, acrescenta regras mais rígidas para a elaboração e a evidenciação de relatórios financeiros nas diferentes esferas do governo.

\subsection{A INSTITUCIONALIZAÇÃO DE PROCEDIMENTOS}

A Institucionalização de procedimentos caracterizada em uma entidade através de hábitos, regras e rotinas (TOLBERT; ZUCKER, 1999; BURNS; SCAPENS, 2000). Através da institucionalização de controles é possível tornar práticas contábeis em habituais e podem ser generalizadas por toda a entidade, e consequentemente, podendo evoluir a um conjunto de verdades e crenças, compondo a cultura da organização, que é autônomo a ação do indivíduo para ser realizada (TOLBERT; ZUCKER, 1999; BURNS; SCAPENS, 2000). Os estudos de Guerreiro, Pereira e Frezatti (2008), Caliman (2014), Junqueira et al. (2015) convergem com esta epistemologia de estudo. Tolbert e Zucker (1999) analisaram o processo de institucionalização e consideraram a existência de três estágios: Habitualização, objetivação e sedimentação. Cada estágio possui um nível diferente de institucionalização, pois determinados padrões de comportamento social são mais suscetíveis à avaliação crítica, modificação e avaliação do que outros.

No processo de Habitualização (pré-institucionalização) desenvolve-se novas técnicas no intuito de mitigar determinados problemas específicos (TOLBERT; ZUCKER, 1999). À medida que novos arranjos são desenvolvidos, novas políticas são criadas e, consequentemente, procedimentos padrões são inseridos, na tentativa de torna-los habituais (TOLBERT e ZUCKER, 1999). No processo de Objetivação (semi-institucionalização), representa o nível de 
concordância dos indivíduos a respeito das práticas, procedimentos e modelos utilizados na entidade, sendo percebidas características mais permanentes e disseminados (TOLBERT; ZUCKER, 1999). É observado o sucesso da adoção de procedimentos em outras entidades para o processo de adoção (TOLBERT; ZUCKER, 1999).

No processo de Sedimentação (institucionalização), representa a institucionalização total da estrutura, pois as práticas e normas instituídas encontram-se plenamente aceitas e enraizadas na cultura da empresa e nas rotinas diárias dos indivíduos da entidade, com capacidade total de sobrevivência e perpetuando assim, ao longo do tempo (TOLBERT; ZUCKER, 1999). No entanto, para que o processo de institucionalização ocorra de forma satisfatória é necessário que os resultados esperados da implantação da estrutura sejam alcançados, que existam promoção, apoios e baixa resistência por parte dos indivíduos inseridos a entidade (TOLBERT; ZUCKER, 1999).

\section{METODOLOGIA DA PESQUISA}

Em relação a abordagem do problema de pesquisa, considerar-se-á como sendo uma pesquisa qualitativa que de acordo com Beuren (2008, p. 92) "concebem-se análises mais profundas em relação ao fenômeno que está sendo estudado. A abordagem qualitativa visa destacar características não observadas por meio de um estudo quantitativo".

Este trabalho classifica-se, quanto aos objetivos, como um estudo de caráter descritivo, no que se refere a verificar o grau de aderência do Governo do Estado do Espírito Santo em relação às Normas Brasileiras de Contabilidade Aplicadas ao Setor Público (NBC - T 16), no intuito de entender o objeto de interesse em um determinado espaço e tempo, descrevendo as características de determinada população ou fenômeno (MARTINS, 1994; GIL, 1999). Quanto a classificação dos procedimentos, o presente trabalho pode ser enquadrado como uma pesquisa documental. Para Marconi e Lakatos (2005, p.176), “a característica da pesquisa documental é que a fonte de coleta de dados está restrita a documentos, escritos ou não, constituindo o que se denomina de fontes primárias".

Neste contexto, a pesquisa foi realizada através de informações encontradas no site do

$\begin{array}{llll}\text { Governo do Estado do } & \text { Espírito }\end{array}$
<http://www.transparencia.es.gov.br/menu_orcamento/prestacao_contas.asp>, com acesso em 18 de agosto de 2016, onde realizou-se o download dos pareceres do Controle Interno (CI) e das Demonstrações Contábeis (DCs) dos respectivos anos.

A comparação realizada teve como base a NBC T 16.6. As demonstrações analisadas foram apenas as que sofrem influência direta com a adoção do regime de competência, são elas: Balanço Patrimonial (BP) e Demonstração das Variações Patrimoniais (DVP).

Destaca-se que optou-se por utilizar as demonstrações contábeis e os pareceres do controle interno dos anos de 2013 a 2015 com o objetivo de explicitar quais as mudanças trazidas pela adoção do regime de competência nos termos do art. 11 da Portaria STN n ${ }^{\circ}$ 634, de 19 de novembro de 2013, que determina os prazos para a adoção do Plano de Contas Aplicado ao Setor Público - PCASP e das Demonstrações Contábeis Aplicadas ao Setor Público - DCASP, para todos os entes da Federação, que expirou com o término do exercício de 2014. Além de considerar os prazos de implantação dos procedimentos contábeis patrimoniais trazidos pela Portaria STN n. ${ }^{\circ} 548$ de 2015.

Complementarmente, este estudo também pretende verificar o estágio de adoção das normas de contabilidade pública no Governo do Estado do Espírito Santo no processo de convergência. A análise das demonstrações financeiras do Governo do Estado do Espírito Santo em equivalência com o processo de convergência das Normas Internacionais de Contabilidade Aplicada ao Setor Público foi realizada com base na Instrução Normativa nº 36/2016 do Tribunal de Contas do Estado do Espírito Santo (TCE ES), levando em consideração os prazos

GєCont, v. 5, n. 1, Floriano-PI, Jan-Jun. 2018. 
por ela delimitados para a adequação das contas do Governo. Ressalta-se que essa normatização segue os prazos nacionais trazidos pela Portaria STN n. ${ }^{\circ} 548$ de 2015.

Foram analisadas as demonstrações dos anos de 2013, 2014 e 2015 em especial o Balanço Patrimonial, a Demonstração das Variações Patrimoniais e as Notas Explicativas, para a obtenção das repostas das questões retiradas da IN nº. 36/2016 do Tribunal de Contas do Espírito Santo e adaptadas pelos autores, como mostra a tabela 1. Foi atribuído o valor 1 (um) para as respostas equivalentes a sim e 0 (zero) para as respostas equivalentes a não, com o total de 18 questões a serem analisadas, criou-se uma escala onde se classifica o atendimento a IN $\mathrm{n}^{\mathrm{o}}$. 36/2016, de 0 a 6 pontos esse atendimento foi considerado "incipiente", de 7 a 12 pontos considerado "intermediário" e de 13 a 18 pontos considerado "avançado". Ressalta-se que alguns dos itens da referida Instrução Normativa possuem prazos futuros, sendo assim, o Governo do Estado não tem obrigatoriedade de tê-los cumprido integralmente.

\section{DESCRIÇÃO E ANÁLISE DOS RESULTADOS}

A análise das demonstrações do período de 2013, 2014 e 2015, em especial o Balanço Patrimonial, a Demonstração das Variações Patrimoniais e as Notas Explicativas, em relação as questões retiradas da IN n ${ }^{\circ}$. 36/2016 do Tribunal de Contas do Espírito Santo e adaptadas pelos autores, é apresentada na tabela 1 . As respostas mostram se os itens foram adotados ou não de acordo com seus respectivos prazos definidos pela IN nº. 36/2016.

Tabela 1 - Resultado dos três anos da análise

\begin{tabular}{|c|c|c|c|}
\hline Procedimentos Contábeis Patrimoniais & 2013 & 2014 & 2015 \\
\hline $\begin{array}{l}\text { 1. Reconhecimento, mensuração e evidenciação dos créditos } \\
\text { oriundos de receitas tributárias e de contribuições (exceto } \\
\text { créditos previdenciários), bem como dos respectivos encargos, } \\
\text { multas, ajustes para perdas e registro de obrigações } \\
\text { relacionadas à repartição de receitas. }\end{array}$ & 0 & 1 & 1 \\
\hline $\begin{array}{l}\text { 2. Reconhecimento, mensuração e evidenciação dos créditos } \\
\text { previdenciários, bem como dos respectivos encargos, multas, } \\
\text { ajustes para perdas. }\end{array}$ & 1 & 1 & 1 \\
\hline $\begin{array}{l}\text { 3. Reconhecimento, mensuração e evidenciação dos demais } \\
\text { créditos a receber, (exceto créditos tributários, previdenciários } \\
\text { e de contribuições a receber), bem como dos respectivos } \\
\text { encargos, multas e ajustes para perdas. }\end{array}$ & 1 & 1 & 1 \\
\hline $\begin{array}{l}\text { 4. Reconhecimento, mensuração e evidenciação da Dívida } \\
\text { Ativa, tributária e não-tributária, e respectivo ajuste para perdas }\end{array}$ & 1 & 1 & 1 \\
\hline $\begin{array}{l}\text { 5. Reconhecimento, mensuração e evidenciação das provisões } \\
\text { por competência }\end{array}$ & 1 & 1 & 1 \\
\hline $\begin{array}{l}\text { 6. Evidenciação de ativos e passivos contingentes em contas de } \\
\text { controle e em notas explicativas. }\end{array}$ & 0 & 0 & 0 \\
\hline $\begin{array}{l}\text { 7. Reconhecimento, mensuração e evidenciação dos bens } \\
\text { móveis e imóveis; respectiva depreciação, amortização ou } \\
\text { exaustão; reavaliação e redução ao valor recuperável (exceto } \\
\text { bens do patrimônio cultural e de infraestrutura). }\end{array}$ & 1 & 1 & 1 \\
\hline
\end{tabular}




\begin{tabular}{|c|c|c|c|}
\hline Procedimentos Contábeis Patrimoniais & 2013 & 2014 & 2015 \\
\hline $\begin{array}{l}\text { 8. Reconhecimento, mensuração e evidenciação dos bens de } \\
\text { infraestrutura; respectiva depreciação, amortização ou } \\
\text { exaustão; reavaliação e redução ao valor Recuperável. }\end{array}$ & 1 & 1 & 1 \\
\hline $\begin{array}{l}\text { 9. Reconhecimento, mensuração e evidenciação das } \\
\text { obrigações por competência decorrentes de empréstimos, } \\
\text { financiamentos e dívidas contratuais e mobiliárias. }\end{array}$ & 0 & 1 & 1 \\
\hline $\begin{array}{l}\text { 10. Reconhecimento, mensuração e evidenciação das } \\
\text { obrigações por competência decorrentes de benefícios a } \\
\text { empregados (ex.: } 13^{\circ} \text { salário, férias, etc.). }\end{array}$ & 1 & 1 & 1 \\
\hline $\begin{array}{l}\text { 11. Reconhecimento, mensuração e evidenciação da provisão } \\
\text { atuarial do regime próprio de previdência dos servidores } \\
\text { públicos civis e militares. }\end{array}$ & 1 & 1 & 1 \\
\hline $\begin{array}{l}\text { 12. Reconhecimento, mensuração e evidenciação das } \\
\text { obrigações com fornecedores por competência. }\end{array}$ & 1 & 1 & 1 \\
\hline $\begin{array}{l}\text { 13. Reconhecimento, mensuração e evidenciação das demais } \\
\text { obrigações por competência. }\end{array}$ & 0 & 0 & 1 \\
\hline $\begin{array}{l}\text { 14. Reconhecimento, mensuração e evidenciação de softwares, } \\
\text { marcas, patentes, licenças e congêneres, classificados como } \\
\text { intangíveis e eventuais amortização, reavaliação e redução ao } \\
\text { valor recuperável. }\end{array}$ & 0 & 1 & 1 \\
\hline $\begin{array}{l}\text { 15. Outros ativos intangíveis e eventuais amortização e } \\
\text { redução a valor recuperável. }\end{array}$ & 1 & 1 & 1 \\
\hline $\begin{array}{l}\text { 16. Reconhecimento, mensuração e evidenciação dos } \\
\text { investimentos permanentes, e respetivos ajustes para perdas e } \\
\text { redução ao valor recuperável. }\end{array}$ & 1 & 1 & 1 \\
\hline 17. Reconhecimento, mensuração e evidenciação dos estoques. & 1 & 1 & 1 \\
\hline $\begin{array}{l}\text { 18. Reconhecimento, mensuração e evidenciação dos demais } \\
\text { aspectos referentes aos procedimentos patrimoniais } \\
\text { estabelecidos nas IPSAS, NBC TSP e MCASP. }\end{array}$ & 0 & 0 & 0 \\
\hline
\end{tabular}

Fonte: Elaborado pelos autores com base na IN no. 36/2016.

No primeiro ano de análise - 2013, constatou-se que o Governo do Estado do Espírito Santo ainda permanecia com suas demonstrações no modelo da Lei $n^{\circ}$. 4.320/1964, ou seja, ainda não possuía uma preparação para o movimento da convergência das NBCASP. Limitando seu Balanço Patrimonial em Ativo Financeiro, Ativo Permanente, Passivo Financeiro e Passivo Permanente, algumas contas deixaram de ser divulgadas ou divulgadas com menor nível de detalhamento, como por exemplo, a conta de depreciação, onde não é evidenciada detalhadamente, não mostrando as depreciações, amortizações e exaustões individuais de cada bem, apenas apresentando o valor do montante total. Várias outras contas também carecem desse nível mais detalhado como regula a IN nº. 36/2016 do Tribunal de Contas do Estado do Espírito Santo.

Observou-se também que algumas contas nem se quer são mencionadas, é o caso dos bens do patrimônio cultural e suas corretas depreciações. Também não foram encontradas informações sobre os ativos e passivos contingentes tanto nas contas de controle quanto nas notas explicativas. Citando estas, averiguou-se que as notas explicativas possuem poucas informações divulgadas e também perecem de certos detalhes, destaca-se que no ano de 2013 não havia uma evidenciação em nível de detalhamento das contas e suas métricas, como exemplo temos as depreciações, não havia um detalhamento dos ativos, tampouco da depreciação individualizada, o que se evidencia é apenas o montante total de cada conta. $\mathrm{O}$ Parecer do Controle Interno esclarece as irregularidades detectadas pela a Auditoria, a GєCont, v. 5, n. 1, Floriano-PI, Jan-Jun. 2018. 
incompatibilidade com os valores da LOA com os descritos na LDO, a não realização de audiência pública para elaboração da LDO e a inobservância ao prazo de repasse do duodécimo aos demais Poderes e Órgãos Autônomos, são alguns dos pontos de distinção. Além disso, notase os pontos que esta auditoria não conseguiu avaliar, como a execução de programas ou projetos de governo não incluídos na LOA e renúncia de receitas - legislação específica. Em suas considerações finais, o Parecer do Controle Interno declara que as demonstrações contábeis e as demais peças que compõe a prestação de contas representam adequadamente a posição financeira, orçamentária patrimonial e de gestão fiscal do exercício a que se refere.

É importante ressaltar que o ano de 2013 numa análise geral, se enquadra nos itens de aplicação imediata nas exigências da IN n $\mathrm{n}^{\circ} .36 / 2016$, já que alguns procedimentos só passam a valer em janeiro de 2016, 2017 e outras em janeiro de 2020. Tendo uma pontuação final de 12 pontos do total de 18 e com o cumprimento de $67 \%$ de todas as demandas da instrução normativa, foram classificados em um nível "intermediário" de atendimento a instrução normativa, o que já pode abrir caminho para um processo de institucionalização. Entretanto, apenas, a adoção de procedimentos não é o suficiente para um processo completo de institucionalização. Deve-se haver comprometimento por parte dos indivíduos, deve-se inserir as práticas nas rotinas do dia-a-dia e, o mais fundamental, deve-se enxergar o procedimento como útil e necessário por todos, para que o processo seja completo.

Abaixo, segue tabela que destaca os itens atendidos e não atendidos neste ano de 2013:

Tabela 2 - Resumo dos procedimentos contábeis patrimoniais atendidos e não atendidos no ano de 2013, conforme a Tabela 1

\begin{tabular}{|c|c|c|}
\hline \multicolumn{3}{|c|}{ Ano 2013} \\
\hline \multicolumn{2}{|c|}{ Itens atendidos } & Itens não atendidos \\
\hline 2. Créditos previdenciários & 10. Benefícios a empregados & $\begin{array}{l}\text { 1. Créditos oriundos de receitas } \\
\text { tributárias e de contribuições }\end{array}$ \\
\hline 3. Créditos a receber & $\begin{array}{l}\text { 11. Provisão de previdência dos } \\
\text { servidores }\end{array}$ & $\begin{array}{l}\text { 6. Ativos e passivos } \\
\text { contingentes }\end{array}$ \\
\hline 4. Dívida ativa & 12. Obrigações com fornecedores & $\begin{array}{l}\text { 9. Empréstimos, financiamentos } \\
\text { e dívidas contratuais e } \\
\text { mobiliárias }\end{array}$ \\
\hline 5. Provisões por competência & 15. Outros ativos intangíveis & 13. Demais obrigações \\
\hline 7. Bens móveis e imóveis & 16. Investimentos permanentes & $\begin{array}{l}\text { 14. Softwares, marcas, patentes, } \\
\text { licenças e congêneres, } \\
\text { classificados como intangíveis }\end{array}$ \\
\hline 8. Bens de infraestrutura & 17. Estoques & $\begin{array}{l}\text { 18. Demais aspectos referentes } \\
\text { aos procedimentos patrimoniais }\end{array}$ \\
\hline
\end{tabular}

Fonte: Elaborado pelos autores.

No ano de 2014, logo no início, percebe-se a mudança da estrutura das demonstrações contábeis, antes, regidas pela Lei $\mathrm{n}^{\circ} .4 .320 / 1964$ e, agora, seguindo a estrutura da NBCT 16.6, creditando um ponto positivo para as demonstrações, visualmente mais limpo e mais organizado, o balanço patrimonial conta com mais informações e as notas explicativas ganharam um nível maior de detalhamento das contas. Todos esses aspectos contribuem para um bom nível de transparência e de usabilidade das informações nelas divulgadas.

No exercício de 2014, o Governo do Estado do Espírito Santo já se mostrou mais avançado com o processo de convergência das normas internacionais, com cumprimento de $83 \%$ da IN n ${ }^{\circ}$. 36/2016, ou seja, cumpriu 15 pontos de um total 18 . Pode-se considerar que o Governo fez avanços relevantes em seus trabalhos de convergência adequando-se a quase todo

GєCont, v. 5, n. 1, Floriano-PI, Jan-Jun. 2018. 
o processo de convergência indicado pela referida Instrução Normativa, tendo em vista que algumas das exigências só começarão a entrar em vigor a partir do ano de 2017 e 2020 . Porém, mesmo assim, o Estado do Espírito Santo já começou a tomar as providências e se adiantar a estes prazos.

Contas que não possuíam detalhamento na divulgação no ano anterior começaram a ganhar seu espaço neste ano, como a divulgação nominal de seus bens intangíveis, imobilizados e móveis, com suas respectivas depreciações, amortizações e exaustões. O reconhecimento, mensuração e evidenciação das obrigações por competências decorrentes de empréstimos neste ano foram totalmente evidenciadas, diferente do ano anterior.

No exercício de 2014, o Parecer do Controle Interno destaca alguns erros detectados pela auditoria, transações entre o Governo do Estado e a CEASA (empresa estatal dependente), que não foram excluídas das demonstrações contábeis consolidadas publicadas, descumprimento do resultado primário, desrespeito ao limite estabelecido na LDO, divergência no saldo contábil das contas bancárias e aplicações. Verificou-se que em alguns itens a Coordenação de Contas do Governo não se manifestou, entre eles, a vinculação de recursos na LOA, execução de receitas e renúncia de receitas. A equipe técnica responsável, não emitiu um parecer conclusivo sobre este ano, apenas levantou os pontos de equívoco do Governo. No entanto, pode-se notar como outro ponto positivo, que as notas explicativas já apresentam-se bem estruturadas, com bom nível de detalhamento, descrição de algumas contas como os Restos a Pagar Não Processados e contas de Empréstimos e Financiamentos à Longo Prazo, tendo esta última especificação de cada montante em cada instituição financeira.

Com o cumprimento de $83 \%$ das exigências da Instrução Normativa o Governo do Estado do Espírito Santo no ano de 2014 se mostrou um pouco mais evoluído na questão da convergência, pois observa-se uma elevação da qualidade da informação, divulgando e aumentando seu nível de transparência e confiabilidade diante dos usuários da informação. Nota-se que neste ano foi alcançado o nível "avançado" na escala de atendimento. Observa-se, a seguir, os itens atendidos e não atendidos na Tabela 3:

\section{Tabela 3 - Resumo dos procedimentos contábeis patrimoniais atendidos e não atendidos} no ano de 2014, conforme a Tabela 1

\begin{tabular}{c|c|c|c}
\hline \multicolumn{2}{c}{ Ano 2014 } & Itens não atendidos \\
\hline $\begin{array}{c}\text { 1. Créditos oriundos de } \\
\text { receitas tributárias e de } \\
\text { contribuições }\end{array}$ & $\begin{array}{c}\text { 7. Bens móveis e } \\
\text { imóveis }\end{array}$ & $\begin{array}{c}\text { 12. Obrigações com } \\
\text { fornecedores }\end{array}$ & $\begin{array}{c}\text { 6. Ativos e passivos } \\
\text { contingentes }\end{array}$ \\
\hline $\begin{array}{c}\text { 2. Créditos } \\
\text { previdenciários }\end{array}$ & $\begin{array}{c}\text { 8. Bens de } \\
\text { infraestrutura }\end{array}$ & $\begin{array}{c}\text { 14. Softwares, marcas, } \\
\text { patentes, licenças e } \\
\text { congêneres, } \\
\text { classificados como } \\
\text { intangíveis }\end{array}$ & 13. Demais obrigações \\
3. Créditos a receber & $\begin{array}{c}\text { 9. Empréstimos, } \\
\text { financiamentos e } \\
\text { dívidas contratuais e } \\
\text { mobiliárias }\end{array}$ & $\begin{array}{c}\text { 15. Outros ativos } \\
\text { intangíveis }\end{array}$ & $\begin{array}{c}\text { 18. Demais aspectos } \\
\text { referentes aos } \\
\text { procedimentos } \\
\text { patrimoniais }\end{array}$ \\
\hline 4. Dívida ativa & $\begin{array}{c}\text { 10. Benefícios a } \\
\text { empregados }\end{array}$ & $\begin{array}{c}\text { 16. Investimentos } \\
\text { permanentes }\end{array}$ & - \\
\hline $\begin{array}{c}\text { 5. Provisões por } \\
\text { competência }\end{array}$ & $\begin{array}{c}11 . \text { Provisão de } \\
\text { previdência dos } \\
\text { servidores }\end{array}$ & 17. Estoques & - \\
\hline
\end{tabular}

Fonte: Elaborado pelos autores.

No último ano de análise o Governo do Espírito Santo prosseguiu com o cumprimento das exigências feitas pela $\mathrm{IN} \mathrm{n}{ }^{\circ} .36 / 2016$, respeitando todos os prazos de cada item, conforme GєCont, v. 5, n. 1, Floriano-PI, Jan-Jun. 2018. 
a NBCT 16.6, com suas demonstrações apresentando um ótimo nível de detalhamento e entendimento por parte do usuário e com estrutura de acordo com tal norma.

Constata-se que com este avanço no exercício de 2015, o Governo do Estado começa a caminhar para um total atendimento dos itens da referida Instrução Normativa. Neste ano foram cumpridas $88 \%$ das exigências, porém com ressalvas, entre elas, a conta de Ativo e Passivo Contingente não teve sua divulgação, porém o Governo em suas Notas Explicativas justificouse da seguinte forma:

"Optou-se por não divulgar maiores informações tendo por base o item 92 da Resolução CFC $\mathrm{N}^{\circ} 1.180 / 09$, que aprovou a Norma Brasileira de Contabilidade TG 25 - Provisões, Passivos Contingentes e Ativos Contingentes, de forma a não prejudicar consideravelmente a posição do Governo do Estado no tocante às ações ajuizadas em relação aos precatórios da trimestralidade" (TCEES, 2016).

Como pontos positivos pode-se citar que as depreciações, amortizações e exaustões foram devidamente detalhadas em Nota Explicativa ao Balanço Patrimonial e no seu Balancete. Créditos Previdenciários e seus ajustes para perdas também foram detalhados em Nota Explicativa, reconhecimento de intangíveis, evidenciação de estoques, bens moveis e imóveis foram outros pontos bem destacados e detalhados nas demonstrações deste ano.

Em 2015 as Notas Explicativas apresentam um nível de detalhe maior do que o encontrado nos anos anteriores, como a descrição da conta "Depósitos de Diversas Origens", onde destaca cada depósito feito e seus respectivos montantes. Os valores arrecadados através de impostos também estão presentes nas Notas Explicativas, com cada valor descriminado detalhadamente, evidencia exatamente o valor arrecadado de cada imposto. Com maiores detalhes o nível de transparência das demonstrações aumenta o que é extremamente importante para o usuário da informação. No Parecer do Controle Interno a equipe técnica constatou em auditoria pequenos desacertos cometidos pelo Governo do Estado, porém não maculam as prestações de contas divulgadas por tal, pelo fato de serem procedimentos de controle passiveis de correção e aperfeiçoamento, dentre outros itens ressaltados, destaca a falta de guarda dos livros contábeis obrigatórios.

Com o cumprimento de 16 itens de um total de 18, o ano de 2015 alcançou o nível "avançado" da escala proposta, se mantendo neste nível mais alto e com maior número de itens atendidos, com $88 \%$ de efetividade propicia a certeza de que o Governo avança evoluindo com seus trabalhos no processo de convergência das normas internacionais e, consequentemente, o processo de institucionalização desses procedimentos. Os resultados do ano de 2015 estão expressos na Tabela 4

Tabela 4 - Resumo dos procedimentos contábeis patrimoniais atendidos e não atendidos no ano de 2015, conforme a Tabela 1

GєCont, v. 5, n. 1, Floriano-PI, Jan-Jun. 2018. 


\begin{tabular}{|c|c|c|c|c|}
\hline \multicolumn{5}{|c|}{ Ano 2015} \\
\hline \multicolumn{4}{|c|}{ Itens atendidos } & Itens não atendidos \\
\hline $\begin{array}{l}\text { 1. Créditos oriundos } \\
\text { de receitas } \\
\text { tributárias e de } \\
\text { contribuições }\end{array}$ & $\begin{array}{l}\text { 7. Bens móveis e } \\
\text { imóveis }\end{array}$ & $\begin{array}{l}\text { 12. Obrigações } \\
\text { com fornecedores }\end{array}$ & 17. Estoques & $\begin{array}{l}\text { 6. Ativos e passivos } \\
\text { contingentes }\end{array}$ \\
\hline $\begin{array}{l}\text { 2. Créditos } \\
\text { previdenciários }\end{array}$ & $\begin{array}{l}\text { 8. Bens de } \\
\text { infraestrutura }\end{array}$ & $\begin{array}{l}\text { 13. Demais } \\
\text { obrigações }\end{array}$ & - & $\begin{array}{l}\text { 18. Demais aspectos } \\
\text { referentes aos } \\
\text { procedimentos } \\
\text { patrimoniais }\end{array}$ \\
\hline 3. Créditos a receber & $\begin{array}{l}\text { 9. Empréstimos, } \\
\text { financiamentos e } \\
\text { dívidas contratuais } \\
\text { e mobiliárias }\end{array}$ & $\begin{array}{l}\text { 14. Softwares, } \\
\text { marcas, patentes, } \\
\text { licenças e } \\
\text { congêneres, } \\
\text { classificados como } \\
\text { intangíveis }\end{array}$ & - & - \\
\hline 4. Dívida ativa & $\begin{array}{l}\text { 10. Benefícios a } \\
\text { empregados }\end{array}$ & $\begin{array}{l}\text { 15. Outros ativos } \\
\text { intangíveis }\end{array}$ & - & - \\
\hline $\begin{array}{l}\text { 5. Provisões por } \\
\text { competência }\end{array}$ & $\begin{array}{l}\text { 11. Provisão de } \\
\text { previdência dos } \\
\text { servidores }\end{array}$ & $\begin{array}{l}\text { 16. Investimentos } \\
\text { permanentes }\end{array}$ & - & - \\
\hline
\end{tabular}

Fonte: Elaborado pelos autores.

Deve-se, porém, ressaltar, que o simples atendimento a um dos itens apontados na Tabela 4, exige esforço por parte da equipe contábil do governo do estado, no sentido de entender todo o processo de reconhecimento, mensuração e evidenciação desse item contábil. Como exemplo, podem ser citadas as normas de Ativo Imobilizado, Ativo Intangível ou Provisão, que possuem em média, 25 páginas cada uma delas; além da contabilização dos registros que são apresentados a parte no Manual de Contabilidade Aplicada ao Setor Público (MCASP) da STN.

Entretanto, apesar dos esforços empreendidos na institucionalização das normas contábeis voltadas para o regime de competência, nota-se que o processo de convergência da contabilidade às normas internacionais do setor público, é ainda incipiente em todo território brasileiro, o que pode ser confirmado pela prorrogação dos prazos dos procedimentos patrimoniais a nível nacional pela Portaria STN n. ${ }^{\circ} 548$ de 2015.

E mesmo, com todas as dificuldades que os órgãos públicos brasileiros enfrentam para institucionalizar as normas convergidas, o governo do Espírito Santo tem conseguido apresentar resultados positivos na evidenciação de melhores informações contábeis patrimoniais.

\section{CONSIDERAÇÕES FINAIS E SUGESTÕES DE PESQUISAS FUTURAS}

Nesta pesquisa foi analisado o processo de adoção da Nova CASP, principalmente a aplicação do regime de competência na contabilidade do setor público. O estudo revela que a implementação do novo sistema de contabilidade baseada no regime de competência pelo Estado do Espírito Santo nos anos de 2014 e 2015, após a adoção das NBCT_16 apresenta um progresso, pois observou-se que os prazos estabelecidos pela instrução normativa (IN n. ${ }^{\circ}$ 36/2016 do TCE ES) têm sido atendidos.

Os resultados permitem observar a evolução na implementação de procedimentos patrimoniais como depreciação, amortização, ajustes para perdas, provisões, apropriações por competência das despesas com pessoal e passivos contingentes.

Os resultados permitem perceber a evolução do Governo do Estado do Espírito Santo, nos períodos analisados, em relação à questão da convergência, pois observa-se uma elevação da qualidade da informação, divulgando e aumentando seu nível de transparência e 
confiabilidade diante dos usuários da informação. Nota-se que neste período foi alcançado o nível "avançado" na escala de atendimento, com o cumprimento de $83 \%$ das exigências da Instrução Normativa do TCE ES.

Nesse contexto, a evolução do conteúdo das Notas Explicativas também pode ser considerada um ponto positivo para a implementação do Regime de Competência e do Processo de Convergência no Governo do Estado do Espírito Santo. Já que esse processo de internacionalização das normas contábeis no setor público surgiu com o objetivo de melhorar a transparência e a qualidade das informações contábeis divulgadas com base no regime de competência (GAMA, 2015).

Em relação aos Relatórios do Controle Interno, deve-se ressaltar que a análise das normas e procedimentos estabelecidos estão sendo cumpridos. Porém, os relatórios apenas possuem a função de salientar os caminhos que estão sendo percorridos que conduzem a um certo resultado, além de gerar eficiência na consecução do objetivo social, o que obviamente, são ferramentas de apoio à contabilidade. A partir de um consistente sistema de controle interno, alcança-se a execução correta, ética, econômica, eficiente e efetiva das operações, o cumprimento das prestações de contas, o cumprimento das leis e regulamentações, que vem ocorrendo de forma escalonada no Governo do Estado do Espírito Santo com a adoção das novas normas de convergência.

Destaca-se a diferenciação dos modelos usados antes e depois da instrução normativa, e o seu impacto positivo sobre a accountability e a transparência neste setor, que contribuem para o fortalecimento da governança pública.

É fato que a melhoria dos procedimentos de accountability demanda além de esforços das equipes contábeis, altos investimentos em infraestrutura com novas tecnologias de informação e recursos humanos, bem como vontade política, que muitas vezes são aspectos carentes no setor público, como ratificam Garrido (2012), Gama e Rodrigues (2016) e Travaglia (2017). Mas, considerando que o processo de convergência das normas contábeis aos padrões internacionais é um processo recente no Brasil, pode-se afirmar que o Governo do Estado do Espirito Santo tem evoluído de forma positiva na institucionalização desses procedimentos contábeis.

Porém, apesar dos avanços aqui relatados, deve-se ressaltar que de acordo com Tolbert e Zucker (1999), a convergência a contabilidade internacional ainda não foi institucionalizada completamente pelo Estado do Espírito Santo. Deve-se salientar que conforme Instrução Normativa TCE-ES $n^{\circ} 36$ de 2016, os prazos para adoção dos procedimentos patrimoniais advindos do regime de competência no setor público ainda não venceram, e sendo assim, o governo do estado do Espírito Santo encontra-se regular perante esta normatização.

Como limitação, salienta-se que os resultados aqui apresentados não podem ser ampliados para pesquisas de outros estados brasileiros, por se tratar de um estudo específico no Governo do Estado do Espírito Santo. Sabe-se que cada estado possui uma regulamentação que pode ser diferente em relação aos prazos de cada tribunal de contas.

Como sugestão de pesquisas futuras, proponha-se que o modelo de pesquisa utilizado, seja aplicado em estados diferentes, a fim de se fazer um estudo comparativo, ou mesmo que seja novamente aplicado no estado do ES, após o término dos prazos estabelecidos pela Portaria STN n. ${ }^{\circ} 548$ de 2015 no que se refere aos procedimentos contábeis patrimoniais, que estendeu o prazo de alguns desses procedimentos para 2024, ampliando assim, também, o processo de institucionalização das novas normas da CASP.

\section{REFERÊNCIAS}

GєCont, v. 5, n. 1, Floriano-PI, Jan-Jun. 2018. 
AMARAL, Guilherme Fernandes; LIMA, Diana Vaz de. A contribuição da nova contabilidade pública sobre os efeitos dos ciclos políticos no Brasil. Revista Ambiente Contábil - UFRN, Natal-RN, v. 5, n. 2, p. 173-18, jul./dez. 2013.

ANTHONY, R. N. GOVINDARAJAN, V. Sistemas de Controle Gerencial. São Paulo: Atlas, 2001.

ANTHONY, R. N. Planning and Control Systems: Framework for Analysis. Boston: Graduate School of Business Administration Harvard University, 1965.

BEUREN, Ilse Maria. Como elaborar trabalhos monográficos em contabilidade: teoria e prática. 3. ed. São Paulo: Atlas, 2008.

BLÖNDAL, Jón R. OECD Journal on Budgeting - Vol. 3, No. 1 - ISSN 1608-7143 - OECD, 2003. Accrual Accounting and Budgeting: Key Issues and Recent Developments.

Disponível em <http://www.oecd.org/dataoecd/21/31/42187847.pdf>

BORGES, Thiago Bernardo et al. Desmitificação do regime contábil de competência. Revista de Administração Pública - RAP, Rio de Janeiro, v. 44, n. 4, p. 877-901, jul./ago. 2010

BRASIL. Lei Complementar $\mathbf{n}^{\mathbf{0}}$ 101, de 04 de maio de 2000. Lei de Responsabilidade Fiscal (LRF). Estabelece normas de finanças públicas voltadas para a responsabilidade na gestão fiscal e dá outras providências. Diário Oficial da República Federativa do Brasil. Brasília, DF, 04 de maio de 2000. Disponível em:

<http://www.planalto.gov.br/ccivil_03/leis/lcp/lcp101.htm>. Acesso em: 23 jun. 2016.

BRASIL. Lei $\mathbf{n}^{\circ}$ 6.404, de 15 de dezembro de 1976. Estatui normas para as Sociedades por Ações. Diário Oficial da República Federativa do Brasil. Brasília, DF, 15 de dezembro de 1976. Disponível em: <http://www.planalto.gov.br/ccivil_03/leis/16404consol.htm>. Acesso em: 23 jun. 2016.

BRASIL. Lei no 4.320, de 17 de Março de 1964, Casa Civil. Estatui Normas Gerais de Direito Financeiro para elaboração e Controle dos Orçamentos e Balanços da União, Estados, Distrito Federal e Municípios. Diário Oficial da República Federativa do Brasil. Brasília, DF, 17 de março 1964. Disponível em: <www.planalto.gov.br/ccivil_03/Leis/L4320.htm>. Acesso 23 ago. 2016.

BRASIL. Ministério da Fazenda. Portaria no. 184, de 25 de agosto de 2008. Dispõe sobre as diretrizes a serem observadas no setor público (pelos entes públicos) quanto aos procedimentos, práticas, elaboração e divulgação das demonstrações contábeis, de forma a torná-los convergentes com as Normas Internacionais de Contabilidade Aplicadas ao Setor Público. Disponível em: <www.fazenda.gov.br>. Acesso em: 23 jun. 2016.

BRASIL. STN - Secretaria do Tesouro Nacional. Manual de contabilidade aplicada ao setor público. Parte III, 3. ed. Brasília: STN, 2010.

BURNS, J.SCAPENS, R. W. Conceptualizing management accounting change: an institutional framework. Management Accounting Research, v. 11, p. 3-25, 2000

CALIMAN, D.R. Fatores que inibem a institucionalização do orçamento como ferramenta de controle gerencial em uma IFES. Dissertação de mestrado. Programa de Pós-Graduação em Administração da Universidade Federal do Espírito Santo, 2014.

CAMPOS, C. V., GAMA, J. R. A Teoria Institucional aplicada à Nova Contabilidade

Pública: Estudo de Casos Múltiplos em Municípios da Grande Vitória/ES. Fucape, 2014. Disponivel em: <

http://www.fucape.br/premio_excelencia_academica/upld/trab/13/Clarissa\%20Vassem\%20Ca mpos_TCC_Edi\%C3\%A7\%C3\%A3o\%202013.pdf>. Acesso em: 15. Dez. 2016.

GєCont, v. 5, n. 1, Floriano-PI, Jan-Jun. 2018. 
CHAN, James L. As NICSPS e a contabilidade governamental de países em desenvolvimento. Revista de Educação e Pesquisa em Contabilidade - REPEC, Brasília, v. 4, n.1, art. 1, p. 1-17, jan./abr. 2010.

CONSELHO FEDERAL DE CONTABILIDADE - CFC. Resolução CFC no. 1.111, de 29 de novembro de 2007. Aprova o Apêndice II da Resolução CFC nº ${ }^{\circ}$ 750/93 sobre os Princípios de Contabilidade.

CONSELHO FEDERAL DE CONTABILIDADE - CFC. Resolução nº 530, de 2 de outubro de 1981. Aprova Princípios Fundamentais de Contabilidade. Norma NBC - T 1.

CONSELHO FEDERAL DE CONTABILIDADE - CFC. Resolução n 750, de 29 de dezembro de 1993. Dispõe sobre os Princípios Fundamentais de Contabilidade.

CRUVINEL, Daniel Pereira; LIMA, Diana Vaz de. Adoção do regime de competência no Setor Público brasileiro sob a perspectiva das normas brasileiras e internacionais de contabilidade. Revista de Educação e Pesquisa em Contabilidade, v. 5, n. 3, art. 4, p. 6985, set./dez. 2011.

CRUZ, Flávio da et al. Lei de responsabilidade fiscal comentada: Lei Complementar $\mathrm{n}^{\circ}$ 101, de 4 de maio de 2000. 2.ed. São Paulo: Atlas, 2001.

ESPÍRITO SANTO (Estado). Instrução normativa TC n⿳0 036, de 23 de fevereiro de 2016. Dispõe sobre os novos prazos-limite de adoção dos procedimentos contábeis patrimoniais aplicáveis ao Estado e aos municípios, em decorrência da Portaria STN no 548, de 24 de setembro de 2015, revoga as Resoluções TC 221/2010, 242/2012, 258/2013 e 280/2014, e dá outras providências. Disponível em: <http://essencialgestaopublica.com.br/wpcontent/uploads/2016/03/IN-036-2016-TCEES-PRAZOS-PARA-ADO\%C3\%87\%C3\%83ODE-PROCEDIMENTOS-CONT\%C3\%81BEIS-port-STN-548-15.pdf>. Acesso em: 05 dez. 2016.

FIGUEIREDO, Carlos M.C et al. Comentários à Lei de Responsabilidade Fiscal. Recife: Nossa Livraria, 2001.

GAMA, J. R.; DUQUE, C. G.; ALMEIDA, J. E. F. Convergência brasileira aos padrões internacionais de contabilidade pública vis-à-vis as estratégias top-dow e bottom-up. Rev.

Adm. Pública, v. 48, n. 1, p.183-206, jan./fev. 2014.

GAMA, Janyluce Rezende. Instrumentos de transparência e acesso às informações públicas: um estudo das demandas por informações contábeis nas universidades federais. 2015. 189 f., il. Tese (Doutorado em Ciência da Informação)—Universidade de Brasília, Brasília, 2015.

GAMA, Janyluce Rezende; NOGUEIRA, Kátia Fialho. Accountability para os convênios das entidades do Terceiro Setor: uma análise da importância do profissional da

contabilidade. Revista Brasileira de Contabilidade, [S.1.], n. 226, p. 44-57, set. 2017. ISSN 2526-8414. Disponível em: <http://rbc.cfc.org.br/index.php/rbc/article/view/1602>. Acesso em: 22 nov. 2017.

GARRIDO, E. P. L. A Lei de acesso às informações públicas. CNM, 2012. Disponivel em: 〈http://www.leideacesso.cnm.org.br/leideacesso/pdf/Artigo_LeideAcessoInformacao.pdf $>$. Acesso em: 14 abr. 2015.

GIL, Antônio Carlos. Métodos e técnicas de pesquisa social. 5. ed. São Paulo: Atlas, 1999.

GUERREIRO, R. PEREIRA, C. A. FREZATTI. F. Aplicação do modelo de Burns e Scapens para avaliação do Processo de Institucionalização da Contabilidade Gerencial. Revista O\&SVol.nº $15-\mathrm{n}^{\circ} 44,2008$.

GєCont, v. 5, n. 1, Floriano-PI, Jan-Jun. 2018. 
HENDRIKSEN, Eldon S; VAN BREDA, Michael F. Teoria da contabilidade. Tradução de Antonio Zoratto Sanvicente. 5. ed. São Paulo: Atlas, 1999.

INTERNATIONAL FINANCIAL REPORTING STANDARDS (IFRS), 2008. Normas Internacionais de Contabilidade. Disponível em: http://www.bradescori.com.br Acesso em: 18 ago. 2016.

JUNQUEIRA, E. R. M. CALIMAN, D. R. PASCUCI, L. M. GONZAGA, R. P. FREZATTI, F. Academia Pratica o Que Ensina? Análise da Institucionalização do Processo Orçamentário em Uma Ifes. XXXIX Encontro da ANPAD, Belo Horizonte, 2015.

LEMES, Sirlei; SILVA, Miriã Gonçalves e. A experiência de empresas brasileiras na adoção das IFRS. Contabilidade Vista \& Revista, Belo Horizonte, v. 18, n. 3, p. 37- 58, julho/setembro 2007.

LIMA, Diana Vaz de; CASTRO, Robinson Gonçalves de. Contabilidade Pública: integrando União, Estados e Municípios (SIAFI e SIAFEM). 3. ed. São Paulo: Atlas, 2009.

LIMA, F.B. LUCA, M.M.M. SANTOS, S.M. PONTE, V. M. R. A Controladoria em Instituições Financeiras: Estudo de Caso no Banco do Nordeste do Brasil S.A. Revista contabilidade Vista e Revista. Universidade Federal de Minas Gerais. Belo Horizonte, v.22, n.1, p- 43-72. jan/ mar 2011.

LOUREIRO, Maria Rita \& ABRÚCIO, Fernando Luiz. Incrementalismo, negociação e accountability: análise das reformas fiscais no Brasil. Coleção Gestão Pública, v.7. Brasília, 2002. (O Estado numa era de reformas: Os anos FHC - Parte 2).

MARCONI, Marina de Andrade; LAKATOS, Eva Maria. Fundamento de metodologia cientifica. 6. ed. São Paulo: Atlas, 2005.

MARTINS, G. A. Manual para elaboração de monografias e dissertações. 2. ed. São Paulo: Atlas, 1994.

MINTZBERG, H. Criando Organizações Eficazes: estruturas em cinco configurações. São Paulo: Atlas, 1995.

NAIDOO, V. Changing Conceptions of Public 'Management' and Public Sector Reform in South Africa. International Public Management Review, Vol. 16, Iss. 1, 2015

NASCIMENTO, Leonardo Silveira do. Contabilidade patrimonial integral no setor público: os parâmetros, desafios e benefícios de sua implementação no Brasil. Brasília: ESAF, 2008.

NASCIMENTO, Leonardo Silveira do. Convergência vai melhorar a transparência no setor público, afirma representante da IFAC. Disponível em:

$<$ http://cfc.org.br/noticias/convergencia-vai-melhorar-a-transparencia-no-setor-publicoafirma-representante-da-ifac/>. Acesso em: 10 ago. 2016.

NIYAMA, Jorge Katsumi; SILVA, César Augusto Tibúrcio. Teoria da contabilidade. São Paulo: Atlas, 2008.

QUINTANA, A. C. JACQUES, S. V. S. MACAGNAN, C.B. Transparency in Municipalities in the Southern Region of Brazil. Journal of Public Administration and Governance, Vol. 6, No. 3, 2016

SACRAMENTO, Ana Rita Silva. Contribuições da lei de responsabilidade fiscal para o avanço da accountability no Brasil. ANPAD. Rio de Janeiro, 2004. Disponível em: 
<http://www.anpad.org.br/diversos/trabalhos/EnANPAD/enanpad_2004/GPG/GPG2447.pdf> . Acesso em: 09 de setembro de 2016.

STN/SOF - Secretaria do Tesouro Nacional e Secretaria do Orçamento Federal. Portaria Conjunta n..$^{\mathbf{1}}$ 1, de 10 de dezembro de 2014. Aprova as Parte I - procedimentos Contábeis Orçamentários da $6^{\mathrm{a}}$ edição do Manual de Contabilidade Aplicada ao Setor Público MCASP, e dá outras providências. Disponível em:

<http://www.tesouro.fazenda.gov.br/documents/10180/456785/CPU_MCASP+6\%C2\%AA\% 20edi\%C3\%A7\%C3\%A3o_Republ2/fa1ee713-2fd3-4f51-8182-a542ce123773>. Acesso em: 08 out. 2016.

TOLBERT, P.S. ZUCKER, L.G. A institucionalização da Teoria Institucional. In: CLEGG, S.R. HARDY, C. NORD, W.R. CALDAS (Org.), M. FACHIN, R. FICHER, T. Handbook de estudos organizacionais: modelos e novas questões em estudos organizacionais. Vol.1. São Paulo: Atlas, p.196 - 219, 1999.

TOLENTINO, M.A. FEITOSA, M. N. SANTIAGO, W. P. DUARTE, S. V. Lei de responsabilidade fiscal: dificuldades e benefícios da implementação e operacionalização na micro mesorregião de Bocaiúva. Unimontes Científica, Montes Claros, v.3, n.3, jun./2002.

TRAVAGLIA, Karina Ramos. Análise Mesorregional da Governança dos Poderes Executivo e Legislativo do Estado do Espírito Santo. 2017. 68 f., Dissertação (Programa de Mestrado em Ciências Contábeis)—Universidade Federal do Espírito Santo, Vitória, 2017.

TRIBUNAL DE CONTAS DA UNIÃO. Referencial básico de governança aplicável a órgãos e entidades da administração pública / Tribunal de Contas da União. Versão 2 - Brasília: TCU, Secretaria de Planejamento, Governança e Gestão, 2014. 80 p.

VANDERHOEK, M. Peter. From Cash to Accrual Budgeting and Accounting in the Public Sector: The Dutch Experience. Public Budgeting \& Finance, 2005.

VIANA, Tácitha Paula de Aguiar; GAMA, Janyluce Rezende. Processo de convergência das normas contábeis aos padrões internacionais: um estudo aplicado à Prefeitura do Município de Vitória (ES).Revista Brasileira de Contabilidade, [S.1.], n. 212, p. 81-91, maio 2015. ISSN 2526-8414. Disponível em: 〈http://rbc.cfc.org.br/index.php/rbc/article/view/1249>. Acesso em: 22 nov. 2017. 